\title{
El tratamiento de la seguridad turística en Brasil en los medios de comunicación españoles antes de los Juegos Olímpicos de Río 2016
}

\section{Treatment of tourist safety in Brazil in the Spanish media before the Olympic Games of Rio 2016}

\author{
Jaime Álvarez de la Torre y Diego R. Toubes ${ }^{1}$ \\ Recibido: 15-05-2017 - Aceptado: 07-08-2017 \\ DOI: https://doi.org/10.26441/RC16.2-2017-A1
}

\begin{abstract}
RESUMEN: La seguridad es uno de los principales problemas actuales del turismo mundial amenazando de manera directa la imagen de cualquier destino. Los medios de comunicación contribuyen a formar parte de esta imagen y proporcionan una percepción de seguridad o inseguridad. Dado que la percepción de inseguridad en Brasil ha sido una de sus debilidades, se plantea la cuestión de cómo influyen los medios en la formación de la imagen ante un gran evento turístico. Se realiza un análisis de contenido sobre el tratamiento de la seguridad turística en Brasil durante 16 meses previos a los JJOO de Río'16 en 1.034 titulares de medios digitales españoles. Se constata un tratamiento excesivamente alarmista/sensacionalista en las temáticas de turismo que se relacionan con la imagen y los JJOO. Aunque en otras áreas del turismo las noticias son más planas y descriptivas es claro que los estereotipos de imagen afloran con ocasión de grandes eventos turísticos.
\end{abstract}

Palabras clave: análisis de contenido; Brasil; imagen; Juegos Olímpicos; medios digitales españoles; seguridad turística.

\begin{abstract}
Safety is one of the main problems of current tourism worldwide and directly threatening the image of any destination. The media contribute to the formation of this image and provide a perception of security or insecurity. Since the perception of insecurity in Brazil has been one of its main weaknesses, the question arises of how the media influence the formation of the image before a major tourist event. A content analysis on the treatment of tourism security in Brazil was carried out for 16 months prior to the Rio'16 Olympic Games in 1,034 Spanish digital media headlines. It is confirmed an excessively alarmist/sensationalist treatment in tourist topics that are related to the image and the Olympic Games. Although in other tourism areas the news is more flat and descriptive it is noticed that stereotypes of image arise on the occasion of major tourist events.
\end{abstract}

Keywords: Brazil; content analysis; Spanish digital media; image; Olympic Games; tourist safety.

1

Jaime Álvarez de la Torre es Doctorando del Programa en Dirección y Planificación del Turismo de la Universidad de La Coruña, Departamento de Sociología, Ciencia Política y de la Administración. jaime.delatorre@udc.es, http://orcid. org/0000-0001-5899-2805

Diego R. Toubes es Profesor del Área de Organización de Empresas y Marketing: Strategic Management de la Facultad de Ciencias Empresariales y Turismo, Universidad de Vigo. drtoubes@uvigo.es, http://orcid.org/0000-0001-7017-6659 


\section{Introducción}

El fenómeno turístico no se concentra en enclaves concretos si no que se ha expandido a todas las regiones del planeta, el estado de bienestar ha ampliado el acceso al turismo a personas de diferentes clases sociales y los avances en el sector del transporte han contribuido al incremento de la movilidad geográfica (Kovari y Zimanyi 2011). Esta globalización del turismo ha contribuido a que cuestiones relativas a la seguridad dejasen de tomarse como hechos aislados pasando a ser un pilar de las políticas turísticas. La inseguridad en el turismo amenaza de manera directa la imagen de cualquier destino. El catálogo de riesgos potenciales que puede afectar al turismo aumenta cada día y en los últimos tiempos el sector ha sido objetivo de ataques terroristas debido a la importancia que tiene para las economías de los países y al poder de difusión e impacto que proporciona el turismo.

La seguridad en un valor que cada vez tiene más peso en la toma de decisión del destino a visitar, principalmente cuando se trata de viajes familiares y/o organizados por tour operadores (Lepp y Gibson 2003; Cavlek 2002). La imagen del destino llega al consumidor a través de diversas fuentes de información siendo los medios de comunicación una de las más influyentes debido a su supuesta presentación imparcial (Gartner, 1994; Kim y Richardson, 2003). Los impactos de los medios de comunicación de masas sobre la imagen orgánica de un destino (aquellas sin fin comercial o promocional) pueden producir cambios en la percepción de los turistas (Potter, 2011). Wang, Chan y Pan (2015) descubrieron cambios en la imagen orgánica de Singapur por efecto de los mensajes difundidos a través de los medios de comunicación. Para los responsables del turismo local es clave proyectar una imagen segura del destino, pero en la mayoría de las ocasiones no tienen el control sobre los medios de comunicación en los mercados emisores por lo que la percepción de seguridad y riesgo que llega al consumidor depende tanto de los hechos como de la forma de información. El caso brasileño es un ejemplo representativo de cómo la realidad social de un país está asociada a estereotipos tanto de carácter positivo como negativo. La inseguridad en Brasil ha sido una de sus debilidades y con ocasión de los Juegos Olímpicos de Río de Janeiro 2016 se convirtió una de las principales preocupaciones. Por este motivo, el análisis de la imagen del destino sobre estos asuntos y ante este tipo de eventos resulta esencial. Ante un evento similar como la Copa del Mundo FIFA de 2010 en Sudáfrica, Hammett (2014) comprobó cómo la prensa británica representaba dicho país desde perspectivas negativas centrándose en aspectos que incitan al miedo y a la inseguridad.

\section{Seguridad turística, imagen y me- dios de comunicación}

El turismo mantiene una estrecha relación con la seguridad con influencias y conexiones en tres ámbitos (Mansfeld y Pizam 2006): naturaleza del incidente que pone en peligro al turismo, siendo las principales fuentes potenciales de 
inseguridad el crimen-delincuencia, terrorismo, guerras e inestabilidad política-civil; impactos en el destino, sociedad, entidades turísticas y demás stakeholders implicados; reacciones de estos stakeholders en el corto, medio y largo plazo.

El concepto de seguridad ha evolucionado desde una perspectiva pasiva hasta convertirse en un factor activo del sector turístico. Según la OMT (2001) la seguridad turística puede ser entendida como la protección de la vida, la salud, la integridad física, psicológica y económica de los visitantes, prestadores de servicios y miembros de las comunidades receptoras. Otros autores añaden una vertiente subjetiva resaltando la importancia de las percepciones y sentimientos de los turistas acerca de un determinado territorio o situación (Blanco 2004; Garmendia 2010). Grünewald (1998) propone una clasificación sobre las distintas dimensiones que engloba el concepto de seguridad turística:

- Seguridad informativa: posibilidad de obtener información sobre la oferta del destino y sus sistemas integrados de prevención.

- Seguridad pública: centrada en asegurar la integridad física del turista minimizando las situaciones de conflicto tales como acciones delictivas o accidentes.

- Seguridad social: protección del turista frente a problemas sociales como huelgas, disturbios o corrupción.

- Seguridad médica: sistema de prevención, control o emergencia médica del visitante durante su desplazamiento por el destino.

- Seguridad en la recreación y en eventos: protección durante la realización o participación en un evento o actividad

- Seguridad vial y de transporte: libre y seguro desplazamiento por las vías de comunicación del destino.

- Seguridad ambiental: protección de las personas en espacios naturales y frente a problemas climatológicos.

- Seguridad en los servicios turísticos: protección del turista en el uso y disfrute de los correspondientes servicios.

\subsection{Formación de la imagen}

El estudio de la imagen en el turismo y las fuentes de información que influyen en la misma está bastante tratado en la literatura científica. Gunn (1988) estableció dos clases de imagen en función del tipo de información que se proporciona el turista. Por un lado, la imagen orgánica es aquella sin finalidad promocional aparente que procede, entre otros, de los medios de comunicación, y la imagen inducida que sería la resultante de todas aquellas acciones de promoción y comunicación dirigidas por las organizaciones o destinos turísticos. Fakaye y Crompton (1991) desarrollaron un modelo de formación de imagen según el cual todos los individuos poseen una imagen orgánica sobre un destino (fuerte o débil), cuando surge la motivación de viajar se activa un proceso de búsqueda activa de información condicionado por dicha imagen orgánica y la experiencia del destino que dará como resultado una imagen inducida y que tras la visita al destino se convertirá en imagen compleja. 
Para cada fase de este proceso los autores recomiendan diferentes tipos de mensajes. Así, el mensaje de tipo informativo es más apropiado en la primera fase puesto que proporciona conocimiento sobre un destino no visitado mientras que una vez seleccionado el destino sería más recomendable un mensaje de tipo persuasivo. Las fuentes de información y la experiencia previa componen los factores de estímulo que se complementa con los elementos psicológicos y sociales (factores personales) (Baloglu y McClearly 1999). Hunt
(1975) y más adelante Gartner (1994) realizan una clasificación de agentes y fuentes de información del turismo. Según Gartner (1994) el proceso de formación de la imagen se puede considerar como un continuo de agentes distintos que actúan independientemente o en combinación para formar una imagen del destino única para el individuo. En la Tabla 1 se presentan las principales fuentes de información de dicho conjunto de agentes formadores de la imagen con la valoración de su credibilidad y de su presencia en el mercado.

Tabla 1. Valoración de la imagen en el turismo según fuente de información

\begin{tabular}{|l|c|c|}
\hline Fuente de información & Credibilidad & $\begin{array}{c}\text { Penetración } \\
\text { de mercado }\end{array}$ \\
\hline Formas tradicionales de publicidad & Baja & Alta \\
\hline Información de TTOO & Media & Media \\
\hline $\begin{array}{l}\text { Promoción aparentemente imparcial por un } \\
\text { personaje público }\end{array}$ & baja/media & Alta \\
\hline Reportajes aparentemente imparciales & Media & Media \\
\hline Noticias y cultura popular & Alta & medio/alta \\
\hline Información no solicitada de amigos y familiares & Media & Baja \\
\hline Información solicitada de amigos y familiares & Alta & Baja \\
\hline
\end{tabular}

Fuente: elaboración propia basada en Gartner (1994)

Los medios de comunicación, en dónde se incluyen todas aquellas noticias, reportajes o documentales sobre los que a priori no existe ninguna intencionalidad de promoción turística, constituyen una de las fuentes con más credibilidad al carecer los encargados de la promoción turística del destino de influencia y control sobre el contenido que se difunda; son los denominados agentes autónomos (Gartner, 1994). De todos modos, es la fuente a la que se le supone un mayor 
grado de imparcialidad y credibilidad por lo que su influencia en la formación de la imagen es considerable. Gartner y Sheen (1992) apuntan que, en función de la importancia del evento sobre el que se informe, existe una amplia a posibilidad de cambiar la imagen en un período relativamente corto de tiempo.

\subsection{Los medios de comunicación ge- neralistas}

Los medios de comunicación constituyen la fuente de información a la que la población está más expuesta por su gran amplitud y difusión y tienen encomendada la función de difundir el conocimiento sobre cualquier rama o actividad de la sociedad (Herrero, 2013) mediante la selección y tratamiento de los diversos hechos que conforman la actualidad. La noticia es la esencia del periodismo y puede definirse como todo hecho novedoso que despierte interés referido a un acontecimiento sorprendente, estremecedor, paradójico, trascendente y sobre todo reciente (Calleja, 2013). Los medios seleccionan las noticias que conforman la actualidad por lo que la opinión pública está en parte condicionada por el énfasis, importancia o recurrencia cómo se traten determinados hechos (Piñuel et al, 2013). Para Wanta y Ghanem (2007) existe una relación directa entre el tratamiento sobre un tema y el grado de preocupación sobre el mismo en la opinión pública. Los medios de comunicación están inevitablemente relacionados con la difusión de noticias de impacto, lo que en ocasiones puede derivar en la creación de una imagen im- precisa o exagerada basada en estereotipos y convirtiéndose en una fuente de prejuicios (Faulkner, 2001; Igartua et al. 2007; R-Toubes, 2010). Los medios dan prioridad a sucesos dramáticos y/o catástrofes a gran escala que suponen una repercusión mediática considerable, pero la cobertura que hacen sobre los riesgos es selectiva; no todos los acontecimientos que conllevan cierto peligro pueden tener una presencia continua en la agenda mediática a pesar de poseer cierto interés periodístico (Eldridge y Reilly, 2003), si bien cuando el turismo es el protagonista de una situación de riesgo, suele tenderse a magnificar el acontecimiento.

El turismo es una actividad que se basa en sensaciones y que requiere de entornos más o menos estables. Los viajeros intentan mitigar la incertidumbre de destinos con alta percepción de riesgo adquiriendo información (Mitchell y Vassos 1998). El proceso de búsqueda de información varía de unos individuos a otros en cuanto a fuentes, procedencia y tipo de información, sin embargo, debido a su gran amplitud y difusión, existe una exposición general a la información facilitada por los medios de comunicación (Fodness y Murray 1997) que como hemos visto, gozan de una elevada credibilidad aunque el tratamiento que cada medio realiza de una noticia provoca la existencia de noticias diferenciadas ante un mismo acontecimiento (Repiso, RodríguezPinto, García-García, 2013). Cualquier información ofrecida por un medio tiene su versión digital a través de las redes sociales. La producción y consumo 
de la información a través de internet se ha consolidado ya sea para tratar temas recurrentes, imprevistos, actuales o en la difusión de meras opiniones (Albornoz, 2007). De todos modos, también existen autores que, como Cantalapiedra y Morán (2006) plantean que la credibilidad de los medios digitales puede verse cuestionada al primar más la inmediatez que el análisis, el contraste o una investigación profunda sobre un hecho que puede producirse más en la prensa escrita.

La mayoría de los estudios sobre la cobertura mediática de los Juegos Olímpicos se centran en aspectos referidos al número de medios acreditados, horas de emisión y demás aspectos promocionales o audiovisuales. Pero cuando el evento en cuestión se celebra en países en desarrollo o con debilidades puede existir la tendencia a un exceso en la difusión de debilidades (Telfer y Sharpley, 2015). D’Hausterre (2004) incluso resalta el modo de informar en países occidentales sobre asuntos de territorios coloniales o periféricos; en estos casos pueden aparecer modos de informar excesivamente estereotipados basados en antiguas relaciones de poder (Cornelissen, 2004). En su estudio sobre la imagen de Sudáfrica en la prensa británica con motivo del Mundial FIFA de 2010, Hammett (2014) detectó la presencia de mensajes que representaban al país como inseguro y peligroso. Pero incluso en el caso de los Juegos de Londres en 2012 hubo estudios previos por parte de la propia prensa británica en la que dudaban sobre la seguridad durante el evento (George y Mawby,
2015) y en otro estudio sobre la prensa australiana, Schroeder y PenningtonGrey (2014) también destacaban el temor a ser víctima de un crimen durante las Olimpiadas.

\section{Objetivo e hipótesis}

Esta investigación se centra en la característica de inseguridad como debilidad estructural y coyuntural de Brasil y sus posibles efectos sobre la imagen en un contexto preolímpico. La inseguridad es una debilidad estructural y una de las principales amenazas en la promoción turística de Brasil, además coyunturalmente la organización de unos Juegos Olímpicos conlleva una serie de impactos que afectan a todas las esferas de la sociedad, sobre todo en lo referente a la imagen turística. Teniendo en cuenta que los JJOO son eventos de gran repercusión mediática, más expuestos por este hecho a los ataques terroristas, y a que los medios de comunicación generalistas son una de las fuentes con mayor grado de credibilidad, el objetivo de este trabajo es conocer la orientación de la agenda mediática sobre Brasil en los medios digitales españoles a efectos del tratamiento que se realice en cuestiones relacionadas con la seguridad y el riesgo en el turismo durante los meses previos a la celebración de los JJOO. La hipótesis que se plantea es que los tipos de expresiones sensacionalistas y/o estereotipadas, alarmistas o informativas en las informaciones varían según la temática de la noticia y su uso puede ser más habitual en caso de grandes eventos o a raíz de determinados acontecimientos. 


\section{Metodología}

La técnica de análisis de contenido permite analizar el mensaje periodístico de modo cuantitativo para una posterior interpretación cualitativa (Urchaga, 2009; Carballa y González, 2014). Se trata de una metodología empleada para descubrir o inferir las intenciones en los productores del mensaje o medir la influencia y los efectos en el público (Igartua, 2006); para ello el análisis de contenido ha de ser sistemático, objetivo y cuantitativo (Kerlinger, 1986). Numerosos estudios realizados en el campo de la comunicación han utilizado esta metodología; dentro del ámbito específico del turismo destacamos el análisis de portadas en prensa española realizado por Rodríguez (2011) o la imagen en prensa de destinos turísticos como Venezuela (Casado, 2014), Sudáfrica (Hammet, 2014) o Singapur (Wang, Chan y Pan, 2015).

Wimmer y Dominck (1996) mencionan dos dimensiones para establecer el universo adecuado: el campo temático y el período de tiempo. Los campos temáticos para la selección de noticias fueron tres: el turismo, los Juegos Olímpicos y los estereotipos de imagen de Brasil. Además, se dividió la temática del turismo en cuatro categorías: política, oferta, demanda y seguridad.

- Política turística: noticias que tengan que ver con indicadores turísticos o de planificación y promoción turística en general.

- Oferta turística: todo lo relativo a componentes que caracterizan la oferta turística y a sus principales recursos.
- Demanda turística: noticias que se centren en aspectos relacionados con los visitantes y turistas a Brasil.

- Seguridad turística: hechos que guarden conexión con alguna de las dimensiones que el concepto seguridad turística aglutina.

El período de recogida de datos tuvo lugar entre Febrero de 2015 y Junio de 2016. La muestra total fue 1.034 noticias procedentes de los siguientes medios: 455 de La Vanguardia, 173 de $E l$ País, 137 de El Economista, $109 \operatorname{del} A B C$, 101 de El Mundo, 25 de La Razón, 24 de Expansión y 10 de Cinco Días.

La unidad de análisis seleccionada fueron los titulares por ser el elemento más representativo de una noticia. El titular es el enunciado más destacado de la noticia aunque en ocasiones también puede comportarse como un texto autónomo al no necesitar de una explicación complementaria (Suárez, 2015). Ya sea desde un punto de vista formal como semántico, el titular es el texto más espectacular; la forma de expresión adquiere especial importancia ya que el objeto de la información es el mismo para todos los medios pero el titular ostenta un carácter diferenciador (Repiso, Rodríguez-Pinto y García, 2013).

Para la clasificación y análisis de los casos seleccionados se elaboró una ficha de análisis de cada titular y se recogió su codificación de acuerdo a las siguientes variables:

1. Relación con el turismo. Se estableció una categorización básica de dos variables: tendrán relación directa todas aquellas noticas referentes a 
datos turísticos como llegadas, pernoctaciones, medio de transporte, etc. así como todas aquellas referencias concretas que afectan a los múltiples sectores que conforman el sistema turístico. Tendrán relación indirecta todas aquellas noticias en las que el turismo no haya sido el protagonista principal de la noticia pero se haya visto afectado de algún modo; como, por ejemplo, el aumento de la criminalidad en cierto destino.

2. Modalidad del titular. Se sigue la clasificación de Martínez Albertos (1993) de titulares: informativos, apelativos, expresivos, temáticos y de cita.

3. Tipo de expresiones. Se consigna la intencionalidad expresiva del titular: informativo, descriptivo, entretenimiento, valorativo, estereotipado y alarmista.

4. Valoración de la noticia. Según el tono, ánimo o intención con el que se difunda el contenido de la noticia, ésta podrá ser positiva, negativa o neutra.

5. Subtema Juegos Olímpicos: la proximidad de la celebración de los JJOO supone un incremento de las noticias acerca de los mismos que afectan a casi todos los ámbitos del destino. En este caso se clasificó según se tratase de aspectos concernientes a seguridad, infraestructuras, asistentes, impactos, población local, deporte, espectáculos y otras.

6. Subtema seguridad turística: como se apuntó en el apartado teórico, se clasifica según el hecho sea relativo a seguridad ciudadana, terrorismo, se- guridad ambiental, seguridad sanitaria, conflictos políticos/sociales y otros.

Los casos seleccionados fueron procesados con el programa estadístico SPSS v.19 mediante el uso de tablas de contingencia ${ }^{2}$. El interés del análisis se centró en el aspecto cualitativo de las relaciones establecidas entre las variables por lo que se muestran los recuentos reales y las frecuencias absolutas teóricas esperadas.

\section{Resultados}

\subsection{Descriptivos de las principales va- riables}

El número de noticias con relación indirecta con el turismo es mayoritario, 731 frente a tan sólo 303 con relación directa. Se entiende como relación directa toda noticia que se refiera específicamente a un sector, agente o indicador turístico en concreto. Organizar unos JJOO tiene un fuerte impacto turístico pero a no ser que la noticia se refiriera específicamente a un aspecto del turismo, no se tuvo en cuenta a efectos de relación directa. Lo mismo ocurre con el apartado de sucesos o seguridad ciudadana, transportes, protestas sociales, problemas sanitarios, etc.

La seguridad, los megaeventos y la imagen turística se encuentran entre los temas tratados más relevantes del corpus de noticias seleccionadas. La seguridad turística concentra el $37.8 \%$ de los casos, las referencias a los JJOO (excluyendo las de carácter exclusivamente deportivo) ocupan la segunda posición con el $23.4 \%$ seguidas por las informaciones sobre determinados recursos o 
aspectos relativos a la oferta turística de Brasil con un $17.1 \%$. Con un $10.3 \%$ nos encontramos con aquellas noticias que tratan aspectos relacionados con la imagen que se tiene del país en el exterior, algunas de ellas con cierta denotación estereotipada, aunque si bien la imagen del país puede estar implícita en cualquiera de las temáticas propuestas.

La crisis derivada de la epidemia del virus del Zika provocó que dentro del tema seguridad turística la seguridad sanitaria haya sido el tema más tratado con 179 casos $(38.7 \%)$, superando a la seguridad ciudadana que con 170 casos (36.8\%) es uno de los problemas estructurales de Brasil. Otro tipo de acontecimientos que afectaron a Brasil durante el periodo de análisis fueron los conflictos políticos (9.3\%) derivados de la grave crisis interna a raíz de escándalos políticos por corrupción o las mismas protestas por el gasto excesivo destinado a los megaeventos deportivos, o indirectamente la amenaza del terrorismo internacional con un $5.2 \%$ de los registros. Con referencia concreta a los JJOO los temas más recurrentes han sido los relacionados con la seguridad, infraestructuras y equipamientos e impactos de dicho evento, aspectos clave a la hora de elaborar una candidatura firme para ser sede del evento (Tabla 2). Seguridad e infraestructura acumulan más de la mitad de las noticias relacionadas con las olimpiadas, 123 casos. Esta mayor cobertura sobre estas cuestiones demuestra la importancia que estos aspectos tienen para la organización de un evento de estas magnitudes.

Tabla 2. Noticias sobre los JJOO

\begin{tabular}{|l|c|c|}
\hline \multicolumn{1}{|c|}{ Variables } & Frecuencia & Porcentaje \\
\hline Seguridad & 68 & $28,2 \%$ \\
\hline Infraestructuras & 55 & $22,8 \%$ \\
\hline Asistentes & 14 & $5,8 \%$ \\
\hline Impactos & 42 & $17,4 \%$ \\
\hline Población local & 6 & $2,5 \%$ \\
\hline Deporte & 19 & $7,9 \%$ \\
\hline Espectáculo & 32 & $13,3 \%$ \\
\hline Otras & 5 & $2,1 \%$ \\
\hline Total & 241 & $100 \%$ \\
\hline
\end{tabular}

2 No se ha calculado el nivel de significatividad debido a la subjetividad existente en la valoración de las noticias y a que en algunos casos las frecuencias esperadas son inferiores a cinco. 
El enfoque de la mayoría de las noticas fue positivo (41.7\%) aunque el número de unidades con valoración negativa es bastante elevado con 378 casos $(36.6 \%)$. Con respecto a la modalidad de titular, la más utilizada fue el tipo informativo en 610 ocasiones (59\%). En segunda posición se sitúan los titulares apelativos con $249(24.1 \%)$ y ya seguidos a mucha distancia de titulares de índole expresiva, de cita y los temáticos.

En línea con la modalidad de titular, el tipo de expresión más recurrente fue el informativo-descriptivo, en un $54.4 \%$ de los casos, sin embargo en la segunda posición se encuentran las expresiones alarmistas con un $22.4 \%$. (Figura 1).

Figura 1. Tipo de expresiones

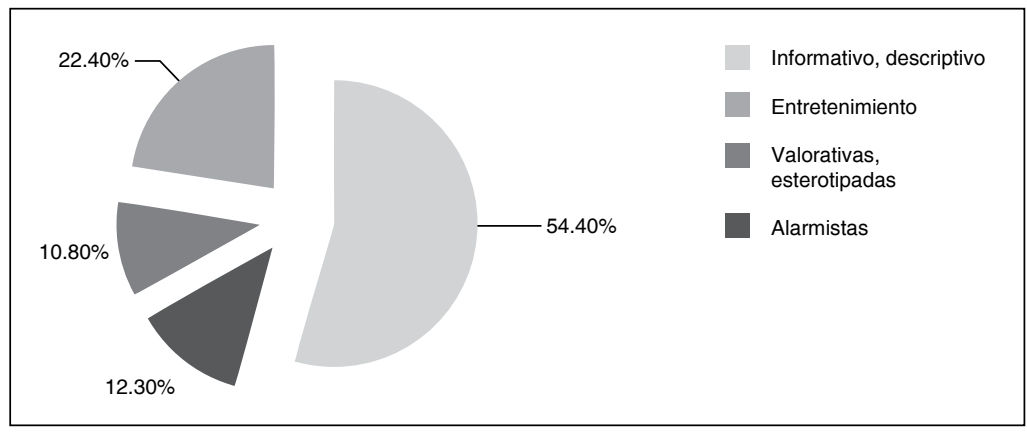

\subsection{Resolución de la hipótesis}

El modo en cómo se difunde el contenido de la noticia señala el enfoque más o menos sensacionalista o descriptivo y puede determinarse en función del tipo de expresión utilizado. Cruzando las variables valoración de la noticia con tipo de expresión, podemos valorar la intencionalidad expresiva de las noticias emitidas según las temáticas analizadas. El tipo de expresión más recurrente fue el informativo/descriptivo con un total de 563 casos de los que 286 tienen una valoración positiva (superior a su frecuencia esperada en 234.7) y 152 una valoración negativa (por debajo de su frecuencia esperada en 205.8). En el caso de las expresiones alarmistas se aprecia un elevado recuento en los registros con valoración negativa (196) en contraste con una presencia casi testimonial de casos con valoración positiva (3) como sería el caso del titular de $E l$ Economista de 12 de Marzo de 2016 "Gobierno Brasileño se declara listo para hacer frente a amenazas biológicas", o en la mismo medio el 2 de Junio de 2016 "Brasil aumenta la seguridad ante las amenazas terroristas en Río".

Las relaciones entre los diferentes temas del ámbito turístico y el tipo de expresión utilizada se presentan en la Figura 2 y en la Tabla 3. En todas las temáticas, exceptuando la imagen, el 
enfoque informativo/descriptivo es el más recurrente. La imagen es la temática en donde más predomina el enfoque valorativo/estereotipado, de las 107 noticias relativas a este tema, 59 utilizaron este estilo, muy por encima de su frecuencia esperada en 11,6. La temática sobre los Juegos Olímpicos utilizó este tipo de expresiones en 30 de los casos. El tipo de expresión alarmista obtiene su mayor resultado en la temática de seguridad turística; de las 391 unidades totales se recurrió a este tipo en 183 casos, siendo muy superior a la frecuencia esperada de 87,7 para dicha temática. Sin embargo, el tipo de expresión informativo/descriptivo dentro de la subtemática seguridad turística es el que obtiene un mayor recuento de casos, 198, estando muy cercano a su frecuencia esperada de 212,9.

Aunque el enfoque informativo/des- criptivo sea el predominante, parece confirmarse que en ocasiones se recurre a ciertas imágenes o ideas sobre Brasil que se encuentran en el imaginario colectivo como la idea de inseguridad, pobreza, desigualdad, discriminación y país con carencias que limitan su desarrollo, o también como destino hospitalario, festivo y alegre (Bignami, 2002). En la Tabla 4 se recogen una serie casos que muestran la idea de Brasil como país de contrastes; en ellos puede apreciarse como para referirse a cuestiones de seguridad suelen optar por titulares muy impactantes mientras que para cuestiones relacionadas con iconos del país como el Carnaval o la musicalidad y sensualidad de sus gentes, se tiende hacia titulares más estereotipados. Por lo tanto si parece que exista un criterio diferente para según que temática se esté tratando.

Figura 2. Tipo de expresión informativo y alarmista según temática

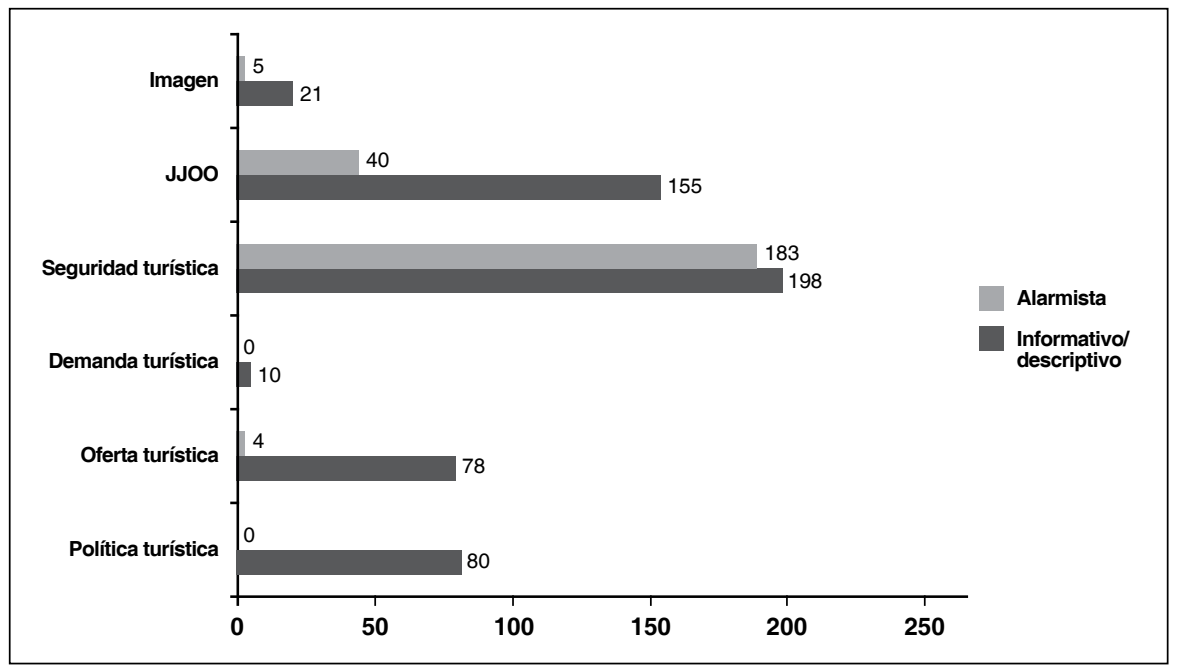


Tabla 3. Tipo de expresión empleada según la temática turística

\begin{tabular}{|c|c|c|c|c|c|c|}
\hline & & & Tipo de exp & esiones & & \\
\hline Iematica & & & & & & Total \\
\hline & Recuento & 80 & 1 & 0 & 0 & 81 \\
\hline turística & Fr. esperada & 44,1 & 9,9 & 8,8 & 18,2 & 81,0 \\
\hline & $\%$ del total & $7,7 \%$ & $0,1 \%$ & $0 \%$ & $0 \%$ & $7,8 \%$ \\
\hline & Recuento & 78 & 82 & 13 & 4 & 177 \\
\hline Oferta & Fr. esperada & 96,4 & 21,7 & 19,2 & 39,7 & 177,0 \\
\hline & $\%$ del total & $7,5 \%$ & $7,9 \%$ & $1,3 \%$ & $0,4 \%$ & $17,1 \%$ \\
\hline & Recuento & 10 & 1 & 2 & 0 & 13 \\
\hline Demanda & Fr. esperada & 7,1 & 1,6 & 1,4 & 2,9 & 13,0 \\
\hline & $\%$ del total & $1,0 \%$ & $0,1 \%$ & $0,2 \%$ & $0 \%$ & $1,3 \%$ \\
\hline & Recuento & 198 & 3 & 7 & 183 & 391 \\
\hline Seguridad & Fr. esperada & 212,9 & 48,0 & 42,4 & 87,7 & 391,0 \\
\hline & $\%$ del total & $19,1 \%$ & $0,3 \%$ & $0,7 \%$ & $17,7 \%$ & $37,8 \%$ \\
\hline & Recuento & 155 & 17 & 30 & 40 & 242 \\
\hline JJOO & Fr. esperada & 131,8 & 29,7 & 26,2 & 54,3 & 242,0 \\
\hline & $\%$ del total & $15,0 \%$ & $1,6 \%$ & $2,9 \%$ & $3,9 \%$ & $23,4 \%$ \\
\hline & Recuento & 21 & 22 & 59 & 5 & 107 \\
\hline Imagen & Fr. esperada & 58,3 & 13,1 & 11,6 & 24,0 & 107,0 \\
\hline & $\%$ del total & $2,0 \%$ & $2,1 \%$ & $5,7 \%$ & $0,5 \%$ & $10,3 \%$ \\
\hline & Recuento & 21 & 1 & 1 & 0 & 23 \\
\hline Otros & Fr. esperada & 12,5 & 2,8 & 2,5 & 5,2 & 23,0 \\
\hline & $\%$ del total & $2,0 \%$ & $0,1 \%$ & $0,1 \%$ & $0 \%$ & $2,2 \%$ \\
\hline & Recuento & 563 & 127 & 112 & 232 & 1034 \\
\hline Total & Fr. esperada & 563,0 & 127,0 & 112,0 & 232,0 & 1034,0 \\
\hline & $\%$ del total & $54,4 \%$ & $12,3 \%$ & $10,8 \%$ & $22,4 \%$ & $100,0 \%$ \\
\hline
\end{tabular}


Tabla 4. Titulares según intención sensacionalista

\begin{tabular}{|c|c|c|}
\hline Periódico & Fecha & Titular \\
\hline EL País & $17 / 2 / 2015$ & Río se desmadra (como cada febrero) \\
\hline El País & $3 / 3 / 2015$ & Brasil, peligroso destino de En tierra hostil \\
\hline El Mundo & 6/6/2015 & Bipolaridad tropical \\
\hline El País & $15 / 6 / 2015$ & Brasil es una minisamba de una única nota \\
\hline $\begin{array}{l}\text { La } \\
\text { Vanguardia }\end{array}$ & 28/6/2015 & $\begin{array}{l}\text { Más de } 3.300 \text { portales de internet promocionan el turismo } \\
\text { sexual en Brasil }\end{array}$ \\
\hline El Mundo & $5 / 8 / 2015$ & Balas y lágrimas en la ciudad olímpica \\
\hline $\mathrm{ABC}$ & 9//8/2015 & $\begin{array}{l}\text { Violencia policial, homicidios y desigualdad: cuando todo } \\
\text { conspira contra los más débiles }\end{array}$ \\
\hline $\begin{array}{l}\text { La } \\
\text { Vanguardia }\end{array}$ & $12 / 8 / 2015$ & $\begin{array}{l}\text { Mayor red social brasileña de sexo se expande a Estados } \\
\text { Unidos e Italia }\end{array}$ \\
\hline Cinco Días & $15 / 8 / 2015$ & Esclavitud y miseria entre los trabajadores de la Villa Olímpica \\
\hline $\mathrm{ABC}$ & $7 / 10 / 2015$ & $\begin{array}{l}\text { Río de Janeiro, donde las aplicaciones de tráfico pueden } \\
\text { llevarte a la muerte }\end{array}$ \\
\hline $\begin{array}{l}\text { La } \\
\text { Vanguardia }\end{array}$ & $28 / 10 / 2015$ & En Brasil tres no son multitud \\
\hline $\mathrm{ABC}$ & $10 / 11 / 2015$ & $\begin{array}{l}\text { El mejor trasero de Brasil tiene } 25 \text { años y es la musa del Sao } \\
\text { Pablo }\end{array}$ \\
\hline El Mundo & $11 / 12 / 2015$ & Fútbol (y muerte) fuera de campo \\
\hline $\begin{array}{l}\text { La } \\
\text { Vanguardia }\end{array}$ & $30 / 1 / 2016$ & $\begin{array}{l}\text { En el Carnaval de Río de Janeiro hasta los niños salen de } \\
\text { parranda }\end{array}$ \\
\hline El Economista & $24 / 2 / 2016$ & $\begin{array}{l}\text { Granados amuebló el piso de su amiga Brasileña en el barrio } \\
\text { de Salamanca con dinero clandestino }\end{array}$ \\
\hline $\mathrm{ABC}$ & $11 / 4 / 2016$ & El poliamor, la última revolución sexual Brasileña \\
\hline El País & $22 / 4 / 2016$ & Tiro a la favela, ¿Deporte olímpico en Río 2016? \\
\hline El Economista & $5 / 5 / 2016$ & EI Disneyland erótico abrirá en Brasil en 2017 \\
\hline El País & $27 / 5 / 2016$ & $\begin{array}{l}\text { Compartir una violación colectiva en las redes, nueva versión } \\
\text { de la barbarie Brasileña }\end{array}$ \\
\hline El País & $29 / 5 / 2016$ & Sueño olímpico o pesadilla sanitaria \\
\hline
\end{tabular}

En la Tabla 5 se muestra el enfoque que se da a la noticia de acuerdo al subtema seguridad turística. El número de noticias en este campo asciende a
462; al tratarse de aspectos concernientes a la seguridad la mayoría de ellos tienen una valoración negativa (309 casos). 
Tabla 5. Valoración de la noticia en seguridad turística.

\begin{tabular}{|c|c|c|c|c|c|}
\hline \multirow{2}{*}{\multicolumn{2}{|c|}{ Subtema seguridad turística }} & \multicolumn{3}{|c|}{ Valoración de la noticia } & \multirow{3}{*}{$\begin{array}{c}\text { Total } \\
170\end{array}$} \\
\hline & & \multirow{3}{*}{$\begin{array}{c}\text { Positiva } \\
15 \\
26,5\end{array}$} & \multirow{2}{*}{$\frac{\text { Negativa }}{139}$} & \multirow{2}{*}{$\begin{array}{c}\text { Neutro } \\
16\end{array}$} & \\
\hline & Recuento & & & & \\
\hline $\begin{array}{l}\text { Seguridad } \\
\text { ciudadana }\end{array}$ & Fr. esperada & & 113,7 & 29,8 & 170,0 \\
\hline & $\%$ del total & $3,2 \%$ & $30,1 \%$ & $3,5 \%$ & $36,8 \%$ \\
\hline \multirow{3}{*}{ Terrorismo } & Recuento & 10 & 8 & 6 & 24 \\
\hline & Fr. esperada & 3,7 & 16,1 & 4,2 & 24,0 \\
\hline & $\%$ del total & $2,2 \%$ & $1,7 \%$ & $1,3 \%$ & $5,2 \%$ \\
\hline \multirow{3}{*}{$\begin{array}{l}\text { Seguridad } \\
\text { ambiental }\end{array}$} & Recuento & 2 & 31 & 3 & 36 \\
\hline & Fr. esperada & 5,6 & 24,1 & 6,3 & 36,0 \\
\hline & $\%$ del total & ,4\% & $6,7 \%$ &, $6 \%$ & $7,8 \%$ \\
\hline \multirow{3}{*}{$\begin{array}{l}\text { Seguridad } \\
\text { sanitaria }\end{array}$} & Recuento & 40 & 101 & 38 & 179 \\
\hline & Fr. esperada & 27,9 & 119,7 & 31,4 & 179,0 \\
\hline & $\%$ del total & $8,7 \%$ & $21,9 \%$ & $8,2 \%$ & $38,7 \%$ \\
\hline \multirow{3}{*}{$\begin{array}{l}\text { Conflicto } \\
\text { político-social }\end{array}$} & Recuento & 3 & 24 & 16 & 43 \\
\hline & Fr. esperada & 6,7 & 28,8 & 7,5 & 43,0 \\
\hline & $\%$ del total &, $6 \%$ & $5,2 \%$ & $3,5 \%$ & $9,3 \%$ \\
\hline \multirow{3}{*}{ Otros } & Recuento & 2 & 6 & 2 & 10 \\
\hline & Fr. esperada & 1,6 & 6,7 & 1,8 & 10,0 \\
\hline & $\%$ del total & ,4\% & $1,3 \%$ & ,4\% & $2,2 \%$ \\
\hline \multirow{2}{*}{ Total } & Recuento & 72 & 309 & 81 & 462 \\
\hline & $\%$ del total & $15,6 \%$ & $66,9 \%$ & $17,5 \%$ & $100,0 \%$ \\
\hline
\end{tabular}

La seguridad sanitaria y la seguridad ciudadana constituyen los asuntos más recurrentes con 179 y 170 casos respectivamente seguidos por los asuntos sobre conflictos político/social (43) y de seguridad ambiental (36). Hechos como la infección por el virus del Zika o la crisis de gobierno en Brasil influyen en el estableci- miento de este orden, en situación de normalidad, la seguridad ciudadana ocuparía el puesto principal en la agenda mediática sobre Brasil. Llama la atención el escaso recuento en cuanto a noticias relacionadas con el terrorismo, 24, siendo la mayoría de valoración positiva, 10, por tan sólo 8 con valoración negativa. 
En ambas situaciones se incumple el patrón de las frecuencias esperadas, lo que puede ser una muestra de la intención por reforzar la imagen de destino seguro y preparado para la celebración de los Juegos Olímpicos. De todos modos no se observan recuentos llamativos en cuanto al tipo de expresión utilizado para la seguridad turística; la desviación más destacada se produce en un uso por encima del esperado de expresiones alarmistas en seguridad ciudadana (96 recuentos frente a 77.6 esperados) si bien no ocurre lo mismo en los casos referidos a terrorismo o seguridad sanitaria.
En la Tabla 6 se pueden ver algunos titulares que alternan intencionalidad informativa o tranquilizadora a otra con tintes un poco más alarmistas. Por ejemplo, destaca el diferente modo de referirse a la seguridad; incluso dentro del mismo medio la utilización de palabras como "prioridad" o "preocupación" denotan un significado diferente a la información (ver titulares 3 y 4 de la Tabla 6). Como señala Calleja (2013), la función de las palabras es describir la realidad pero también pueden crearla según cuál sea el término escogido.

Tabla 6. Titulares sobre impacto de terrorismo en los JJOO

\begin{tabular}{|l|l|l|}
\hline Periódico & Fecha & Titular \\
\hline La Vanguardia & $21 / 11 / 2015$ & $\begin{array}{l}\text { Los atentados de París elevan los temores por la seguridad } \\
\text { en los Juegos Olímpicos de Río 2016 }\end{array}$ \\
\hline El País & $24 / 11 / 2015$ & $\begin{array}{l}\text { Brasil confía en la seguridad de Rio 2016, pero no baja la } \\
\text { guardia }\end{array}$ \\
\hline El País & $28 / 11 / 2015$ & $\begin{array}{l}\text { La seguridad pasa a ser la mayor preocupación de las } \\
\text { Olimpiadas de Río }\end{array}$ \\
\hline El Economista & $28 / 11 / 2015$ & $\begin{array}{l}\text { Brasil trabaja con hipótesis de "amenaza inminente" para } \\
\text { seguridad de Rio-2016 }\end{array}$ \\
\hline El Economista & $18 / 12 / 2015$ & $\begin{array}{l}\text { Brasil confía en las medidas adoptadas para prevenir } \\
\text { atentados en Río 2016 }\end{array}$ \\
\hline El Economista & $3 / 3 / 2016$ & $\begin{array}{l}\text { Brasil preocupada por posible actuación de lobos solitarios } \\
\text { durante Juegos }\end{array}$ \\
\hline La Vanguardia & $12 / 3 . / 2016$ & $\begin{array}{l}\text { Brasil garantiza la seguridad en los Juegos Olímpicos con } \\
\text { las alarmas en rojo }\end{array}$ \\
\hline La Vanguardia & $18 / 4 / 2016$ & $\begin{array}{l}\text { Confirman en Brasil autenticidad de amenaza terrorista del } \\
\text { Estado Islámico }\end{array}$ \\
\hline
\end{tabular}


Aparte de la preocupación por el terrorismo, la capacidad, adecuación o idoneidad de ciertas infraestructuras o servicios para las Olimpiadas del país también fue objeto de un tratamiento en ocasiones demasiado expresivo, como puede verse en la Tabla 7. Por lo que puede probarse también que la organización de unos JJOO incrementa el nivel de exigencia mediático sobre el destino.

Tabla 7. Titulares sobre infraestructuras de los JJOO.

\begin{tabular}{|l|l|l|}
\hline Periódico & Fecha & Titular \\
\hline La Vanguardia & $10 / 3 / 2015$ & $\begin{array}{l}\text { Sede de vela de los JJOO sigue pareciendo vertedero a 514 } \\
\text { días de Río 2016 }\end{array}$ \\
\hline La Vanguardia & $25 / 3 / 2015$ & $\begin{array}{l}\text { Río de Janeiro minimiza la amenaza de polución para la vela } \\
\text { en JJOO 2016 }\end{array}$ \\
\hline El Mundo & $30 / 7 / 2015$ & Alerta sanitaria en Río: las aguas putrefactas son un peligro \\
\hline El País & $2 / 8 / 2015$ & $\begin{array}{l}\text { Mario Moscatelli: "Que los regatistas se vacunen de la } \\
\text { hepatitis A" }\end{array}$ \\
\hline La Vanguardia & $22 / 2 / 2016$ & $\begin{array}{l}\text { El agua "fecal" en la que tendrán que competir los atletas de } \\
\text { los JJ.OO. }\end{array}$ \\
\hline
\end{tabular}

Con respecto al virus del Zika, su tratamiento fue variando a lo largo del tiempo; desde las dudas y sorpresas iniciales, hasta el continuo goteo y aumento de casos confirmados con sus consiguientes impactos y reacciones sobre la incidencia y las repercusiones que podrían acarrear para la celebración de los JJOO. En la Tabla 8 puede apreciarse la evolución en el tratamiento mediático que esta "crisis" ha ido teniendo a través de algunos ejemplos de noticias. 
Tabla 8. Titulares sobre evolución crisis del Zika

\begin{tabular}{|c|c|c|}
\hline Periódico & Fecha & Titular \\
\hline El Mundo & $8 / 12 / 2015$ & $\begin{array}{l}\text { Brasil investiga } 1761 \text { casos sospechosos de microcefalia } \\
\text { y } 19 \text { muertes }\end{array}$ \\
\hline El País & $15 / 1 / 2016$ & $\begin{array}{l}\text { Alerta en Brasil por el crecimiento exponencial de } \\
\text { microcefalia en bebés }\end{array}$ \\
\hline La Vanguardia & $17 / 1 / 2016$ & $\begin{array}{l}\text { Ministro de Salud ve "prudente" recomendación de EE. } \\
\text { UU. de no viajar a Brasil }\end{array}$ \\
\hline El Economista & $19 / 1 / 2016$ & $\begin{array}{l}\text { El temor por el virus Zika se expande en Brasil de cara al } \\
\text { Carnaval y a los Juegos Olímpicos }\end{array}$ \\
\hline El País & $20 / 1 / 2016$ & "La situación causada por el virus zika es dramática" \\
\hline $\mathrm{ABC}$ & $22 / 1 / 2016$ & $\begin{array}{l}\text { Alarma en Brasil: los casos de bebés con microcefalia } \\
\text { saltan de } 300 \text { a casi } 3.900 \text { en } 3 \text { meses }\end{array}$ \\
\hline El País & $28 / 1 / 2016$ & $\begin{array}{l}\text { Alarma en Brasil: los casos de bebés con microcefalia } \\
\text { saltan de } 300 \text { a casi } 3.900 \text { en } 3 \text { meses }\end{array}$ \\
\hline La Vanguardia & $29 / 1 / 2016$ & $\begin{array}{l}\text { Las noticias internacionales del día: Las Olimpiadas de } \\
\text { Río podrían expandir en Zika a nivel mundial }\end{array}$ \\
\hline La Vanguardia & $29 / 1 / 2016$ & $\begin{array}{l}\text { Detectan en Austria primer caso de zika en una turista } \\
\text { que regresó de Brasil }\end{array}$ \\
\hline La Vanguardia & 2/2/2016 & $\begin{array}{l}\text { Brasil descarta riesgo por el zika para la mayoría de } \\
\text { turistas en JJOO }\end{array}$ \\
\hline El País & 9/2/2016 & Ir a los Juegos, una decisión "personal" \\
\hline $\mathrm{ABC}$ & $12 / 2 / 2016$ & Confirman la tercera muerte por causa del Zika en Brasil \\
\hline $\mathrm{ABC}$ & $13 / 2 / 2016$ & $\begin{array}{l}\text { Ejército y Científicos Brasileños, cada vez más } \\
\text { preparados para combatir el Zika }\end{array}$ \\
\hline El Mundo & $17 / 2 / 2016$ & $\begin{array}{l}\text { Sanidad elabora una guía sobre Zika de cara a los } \\
\text { Juegos Olímpicos }\end{array}$ \\
\hline $\mathrm{ABC}$ & $25 / 2 / 2016$ & $\begin{array}{l}\text { La OMS garantiza la seguridad de atletas y visitantes } \\
\text { frente al zika }\end{array}$ \\
\hline El Economista & $11 / 5 / 2016$ & $\begin{array}{l}\text { La OMS expresa confianza en las medidas de Brasil } \\
\text { contra el zika de cara a los Juegos Olímpicos }\end{array}$ \\
\hline La Vanguardia & $28 / 5 / 2016$ & $\begin{array}{l}\text { La OMS rechaza cambiar el lugar de celebración de los } \\
\text { JJOO por el Zika }\end{array}$ \\
\hline El País & $31 / 5 / 2016$ & Zika, un "riesgo controlado" en Río \\
\hline Cinco Días & $31 / 5 / 2016$ & $\begin{array}{l}\text { El zika amenaza los Juegos de Río y } 25.000 \text { millones de } \\
\text { euros }\end{array}$ \\
\hline
\end{tabular}




\section{Discusión}

Aunque más de la mitad de las noticias analizadas son meramente informativas, un número importante, el $22.4 \%$, son de tipo alarmistas. Este tipo de noticias se muestra muy vinculado a un enfoque negativo (el $84.4 \%$ de las noticias alarmistas) por lo que encontramos una marcada intencionalidad expresiva negativa en las noticias publicadas durante este periodo. El número total de noticias con enfoque negativo es muy alto (36.6\%), en parte puede deberse al enfoque que cada medio haya utilizado respecto a un asunto como el del virus del Zika. El 21.8\% de noticias con valoraciones neutras puede relacionarse también como un ejercicio de cautela respecto al modo de informar sobre este asunto. La influencia de una valoración neutra sobre la percepción de imagen de un país puede adquirir tanto un carácter positivo o negativo.

Organizar unos JJOO supone todo un desafío y requiere un nivel de exigencia muy elevado pero la recompensa en términos de imagen y promoción constituye uno de los principales beneficios sostenibles del evento. Aunque no se observa un uso excesivo del enfoque sensacionalista, los tipos de expresión estereotipada y alarmista obtienen valores considerables en determinadas temáticas como la Imagen o los JJOO. La intencionalidad expresiva de tipo valorativo o estereotipado latente en las noticias con ocasión de los JJOO apoya la hipótesis planteada al comienzo del trabajo. Comprobar los impactos de estos mensajes en el receptor requeriría disponer de una muestra de visitantes so- bre la que poder medir las posibles variaciones de la imagen previa (imagen orgánica) y posterior del destino (imagen compleja) y comprobar en qué medida las informaciones difundidas por los medios afectan a factores relacionados con la percepción del riesgo y por lo tanto a su imagen. Gartner (1994) señala que los mensajes difundidos desde los medios de comunicación pueden provocar un cambio en la imagen en un plazo relativamente corto de tiempo en función de la magnitud e impacto del evento o suceso, pero sin existir un mensaje de refuerzo, dicho cambio no debería perdurar en el tiempo. En nuestro caso las continuas referencias sobre inseguridad y sucesos pueden haber sido establecidas como mecanismo de defensa ante la eventualidad de posibles riesgos turísticos. De todos modos, en línea con lo apuntado por Davara, López Martínez-Fresnada y Sánchez (2004) ante acontecimientos extraordinarios, sean o no dramáticos, suele adoptarse una visión más informativa. En nuestro caso, con una elevada amenaza terrorista a nivel mundial y con el inicio de una epidemia sanitaria (con todas las dudas que eso conlleva), incluso podría parecer que el número de casos con tipos de expresiones alarmistas no haya sido muy elevado. La figura 3 refleja las esferas en la que estuvo involucrado Brasil desde un punto de vista temporal y geográfico $\mathrm{y}$ ante las que otros destinos a nivel mundial no pudieron hacer frente sufriendo importantes pérdidas para el sector en términos económicos y de imagen, como podrían ser en los casos de destinos de Oriente Medio como Egipto o Turquía. 
Figura 3. Esquema de riesgo desde perspectiva temporal y geográfica

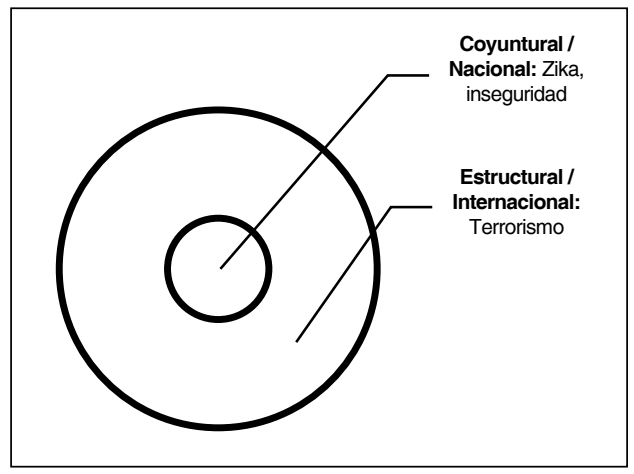

El análisis de contenido realizado presenta un alto grado de subjetividad en la valoración de las variables de enfoque de la noticia y tipo de expresión, y menos en la clasificación de las temáticas del turismo y seguridad turística. Sin embargo, parece claro que los medios de comunicación dedican una atención sistemática a acontecimientos que se corresponden con el imaginario colectivo sobre los atributos de Brasil. Las temáticas publicadas parecen seguir fundamentándose en los principales atributos del país y vienen a mostrar que la denominación de Brasil como país de contrastes tiene una base sólida y que sigue habiendo una serie de estereotipos.

\section{Conclusiones}

La coyuntura en la que se desarrolló esta investigación recrea distintos escenarios sobre los que se basan las teorías sobre percepción de riesgo turístico. Cuestiones referidas a seguridad ciudadana, ambiental, sanitaria o terrorismo influyeron en mayor o menor medida en la imagen que Brasil transmitía al resto del mundo en los meses previos a la celebración de los Juegos. La agenda mediática estuvo marcada por una serie de acontecimientos, algunos imprevistos y otros más habituales, susceptibles de producir variaciones en el modo de percibir ciertos asuntos en la audiencia, y por lo tanto, susceptibles de influir en la formación de la imagen de un destino. A riesgos ya conocidos como la inseguridad ciudadana en Brasil o la amenaza terrorista a nivel mundial, se les añadió la incertidumbre creada por el brote del virus del Zika justo en los momentos previos a la celebración de los Juegos; incidente sanitario con una valoración dispar según qué colectivo o sector opinase sobre el mismo.

El poder de influencia de los medios de comunicación como fuente de información no reside tanto en qué se cuenta, sino en cómo, cuándo y cuánto, es decir, su frecuencia de aparición. Ante un destino como Brasil o ante la celebración de unos JJOO se supone que 
los visitantes demandarán mensajes de tipo informativo, por lo que ésta debería ser la recomendación principal. En nuestro caso, a pesar de que la mayoría de noticias han sido de tipo informativo, que determinados hechos hayan sido narrados de manera alarmista ha podido generar un incremento en la percepción del riesgo. De todas maneras tampoco debe atenderse únicamente a una mera cuantificación o recuento de las variables analizadas ya que el nivel de impacto de hechos relativos a la seguridad turística no dependen tanto de su recurrencia sino de otra serie de características como difusión, sectores implicados, etc. Un acontecimiento aislado, con un tratamiento mediático intensivo, puede tener mayor capacidad de influencia que toda la agenda mediática rutinaria sobre un destino. En este tipo de disciplina los datos estadís- ticos no han de ser interpretados estrictamente, basta con consultar las diferencias entre las frecuencias esperadas y los recuentos efectuados para comprobar que el uso del tipo de expresión alarmista es de difícil predicción con independencia de la valoración de la noticia o de la temática.

A pesar de la importancia de los medios de comunicación, no parece que en este caso hayan sido un factor decisivo en el comportamiento de la demanda turística. Hechos de tanta importancia como la crisis del virus del Zika, la amenaza terrorista o la inseguridad ciudadana han sido protagonistas de la agenda mediática sobre Brasil durante el período previo a la celebración de los Juegos Olímpicos haciendo patente que es un país de contrastes, ya no sólo en cuanto a términos de imagen, sino también en cuanto a repercusión mediática.

\section{Referencias Bibliográficas}

Albornoz, L. (2007). Periodismo digital: Los grandes diarios en la red La Crujía.

Baloglu, S., \& McCleary, K. W. (1999). A model of destination image formation. Annals of Tourism Research, 26(4), 868-897.

Bignami, R. (2002). A imagem do brasil no turismo: Construção, desafios e vantagem competitiva Aleph. Blanco, F. J. (2004). Reflexiones sobre seguridad, poderes públicos y actividad turística. Estudios turísticos, (160), 5-30.

Calleja, J. M. (2013). La violencia como noticia. Catarata.

Cantalapiedra, M. J., \& Morán, P. (2006). Nuevas expresiones, nuevos públicos. In Tendencias 06, Medios de comunicación: el año de la televisión (pp. 381-394). Fundación Telefónica.

Carballa, N. M. \& González, A. G. (2014). Tratamiento periodístico de la prohibición de las corridas de toros en Cataluña en la prensa nacional española desde la perspectiva del framing/The informative treatment of bullfights in Spanish national press. An analysis of content from the Framing perspective. Estudios sobre el Mensaje Periodístico, 20(2), 969.

Casado Gutiérrez, F. (2014). Venezuela en la prensa internacional: procesos de información y desinformación. Universidad de la Laguna.

Cavlek, N. (2002). Tour Operators and destinations safety. Annals of Tourism Research, 29(2), 478-496. 
Cornelissen, S. (2004). 'It's africa's turn!'the narratives and legitimations surrounding the moroccan and south african bids for the 2006 and 2010 FIFA finals. Third World Quarterly, 25(7), 1293-1309.

d'Hauteserre, A. M. (2004). Postcolonialism, colonialism, and tourism. A companion to tourism, 235.

Davara, J., López, P., Martínez-Fresnada, H., \& Sánchez, G. (2004). España en portada. análisis de las primeras páginas de los diarios nacionales y su influencia en la sociedad.

Eldridge, J., \& Reilly, J. (2003). Risk and relativity: BSE and the british media. The Social Amplification of Risk, , 138.

Fakeye, P. C., \& Crompton, J. L. (1991). Image differences between prospective, first-time, and repeat visitors to the lower rio grande valley. Journal of Travel Research, 30(2), 10-16.

Faulkner, B. (2001). Towards a framework for tourism disaster management. Tourism management, 22(2), 135-147.

Fodness, D., \& Murray, B. (1997). Tourist information search. Annals of tourism research, 24(3), 503-523.

Garmendia, I. (2010). Plan de protección al turista. Lima. Perú: Ministerio de Comercio Exterior y Turismo.

Gartner, W. C. (1994). Image formation process. Journal of Travel छ Tourism Marketing, 2(2-3), 191-216.

Gartner, W. C., \& Shen, J. (1992). The impact of Tiananmen Square on China's tourism image. Journal of Travel Research, 30(4), 47-52.

George, R., \& Mawby, R. I. (2015). Security at the 2012 london olympics: Spectators' perceptions of london as a safe city. Security Journal, 28(1), 93-104.

Grünewald, L. (1998). La seguridad en la actividad turística. Secretaria De Turismo De La Nación, Universidad Del Salvador y Cámara De Empresarios Hoteleros De Villa Gesell.10pp,

Gunn, C. A. (1988). Vacationscape: Designing tourist regions. Van Nostrand Reinhold.

Hammett, D. (2014). Tourism images and British media representations of South Africa. Tourism Geographies, 16(2), 221-236.

Herrero, E. (2013). Periodistas y redes sociales en España. Del 11M al 15M (2004-2011). Universidad Carlos III, Madrid.

Hunt, J. D. (1975). Image as a factor in tourism development. Journal of Travel Research, 13(3), 1-7. Igartua, J. J. (2006). Métodos cuantitativos de investigación en comunicación. Barcelona: Bosch.

Igartua, J. J., Muñiz, C., Otero, J. A., \& De la Fuente J, M. (2007). El tratamiento informativo de la inmigración en los medios de comunicación españoles. Un análisis de contenido desde la Teoría del Framing. Estudios sobre el Mensaje Periodístico, 13, 91-110.

Kim, H., \& Richardson, S. L. (2003). Motion picture impacts on destination images. Annals of Tourism Research, 30(1), 216-237.

Kovari, I., \& Zimanyi, K. (2011). Safety and security in the age of global tourism (the changing role and conception of safety and security in tourism). ABSTRACT: Applied Studies in Agribusiness and Commerce, 5 
Lepp, A. y Gibson, H. (2003). Tourist roles, perceived risk and international tourism. Annals of Tourism Research, 30(3), 606-624.

Martínez Albertos, J. L. (1993). Curso general de redacción periodística. Madrid: Paraninfo.

Mansfeld, Y., \& Pizam, A. (2006). Tourism, security and safety: From practice to theory.

Mitchell, V. W., \& Vassos, V. (1998). Perceived risk and risk reduction in holiday purchases: A cross-cultural and gender analysis. Journal of Euromarketing, 6(3), 47-79.

OMT. (2001). EL Turismo después del 11 de Septiembre. Medidas Correctoras”. Madrid

Piñuel, J. L., Gaitán, J. A., \& Lozano, C. (2013). Confiar en la prensa o no. Un método para el estudio de la construcción mediática de la realidad. Salamanca, Comunicación Social Ediciones y Publicaciones.

Potter, J. W. (2011). Conceptualizing mass media effect. Journal of Communication, 61 (5), 896-915

Repiso, R., Rodríguez-Pinto, M. Á., \& García, F. G. (2013). Posicionamiento y agrupación de la prensa española: Análisis de contenido de las noticias generadas en la Jornada Mundial de la Juventud 2011. Estudios sobre el Mensaje Periodístico, 19(2), 1091-1106.

Rodríguez Ruibal, A. (2011). Análisis del turismo en las portadas de El País y El Mundo,(2006-2009). Universidad Complutense de Madrid, Servicio de Publicaciones.

Rodríguez, A. (2009). Periodismo turístico: análisis del turismo a través de las portadas (Vol. 144). Editorial UOC.

Rodríguez-Toubes, D., \& Fraiz, J. A. (2012). Recomendaciones de viaje a países en vías de desarrollo: El caso de Kenia como destino emergente. Gestión de destinos turísticos, Congreso AECIT 2012, Carballiño, 162-172

Schroeder, A., \& Pennington-Gray, L. (2014). Perceptions of crime at the olympic games what role does media, travel advisories, and social media play? Journal of Vacation Marketing, 20(3), 225-237.

Suárez Ramírez, S. (2015). Los titulares en los cibermedios deportivos. Principales figuras retóricas y su aplicación didáctica. Tesis Doctoral. Universidad de Extremadura.

Telfer, D. J., \& Sharpley, R. (2015). Tourism and development in the developing world. Routledge. Urchaga, J. D. (2009). Análisis de Contenido. Reyes, R. Diccionario Crítico de Ciencias Sociales, 1, 147-151.

Wang, D., Chan, H., \& Pan, S. (2015). The Impacts of Mass Media on Organic Destination Image: A Case Study of Singapore. Asia Pacific Journal of Tourism Research, 20(8), 860-874.

Wanta, W., \& Ghanem, S. (2007). Effects of agenda setting. Mass media effects research: Advances through meta-analysis, 37-51.

Wimmer, R. D., \& Dominick, J. R. (1996). La investigación científica de los medios de comunicación: Una introducción a sus métodos. Barcelona: Bosch. 